as to make it a vital factor in public opinion; the other is to restrain any such development of an authoritative and perhaps embarrassing criticism of the conduct of public affairs and to keep the man of science modestly to his present subordination."

Mr. Wells is of the opinion that great possibilities await scientific research if his new and stirring education increased the numbers of workers available. "I throw out the suggestion that in our present-day world, of all the brains capable of great and masterful contributions to 'scientific' thought and achievement, not one in a thousand, not one in a score of thousands, ever gets born into such conditions as to realise its opportunities. And of the millions who would make good, useful, eager secondary research workers and explorers, not one in a million is utilised."

Mr. Wells writes with a strong sense of urgency. For the better part of his life this prolific and ingenious writer has been one of the foremost of our propagandists for an outlook which is at the same time scientific and humane. It has now become a question how far the scientific outlook is necessarily bound up with humane and liberal ideals, and perhaps Mr. Wells is too ready to take such a connexion for granted. For this reason it is perhaps a pity that Mr. Wells is so impatient of the traditional religions, for though in the past they may have been, and may sometimes still be, obstacles to progress, yet they too are capable of leading men to make "mental readjustments" of a desirable kind. To take one example. According to the Hindu view of life, when a man has reached a certain age and fulfilled certain responsibilities, he should retire from active life and devote himself to the contemplation of the ultimate mysteries. Mr. Wells might consider this a waste of time; but by banishing all the men of sixty from active life it would ease the situation of those surplus and frustrated young men whose existence Mr. Wells regards as the chief cause of wars.

J. C. HARDWICK.

\section{GENETICS APPLIED}

New Paths in Genetics

By Prof. J. B. S. Haldane. Pp. 206. (London : George Allen and Unwin, Ltd., 1941.) 7s. 6d. net.

T the thirty-three years that have elapsed since Bateson wrote his "Principles", two kinds of activity have developed from that book. The one has been concerned with digging the foundations of genetics deeper and the other with building a superstructure of more immediate utility. One has led to an integration with the physiology and mechanics of the chromosomes and of the cell; the other is leading, by a more laborious process, to an integration with plant breeding in general and with special problems in embryology, biochemistry and medicine.

So far as plant breeding goes, the first attempts to build on the Batesonian foundation were partly disappointing. That was bound to be so because in the formal genetics of Bateson the chromosomes are treated as symbols obeying deductively the established laws of the subject. Unfortunately, the easiest achievements as well as the greatest difficulties in plant breeding depend on the chromosomes disobeying these laws. Moreover, the statistical instruments for handling plant breeding, even so far as the laws held, were not at first available, and have not yet been systematically applied.

In other directions, however, Bateson's formulæ hold well enough for practical purposes, and it has been possible ever since 1909 to go ahead with elucidating their applications to the problems which other branches of biology are continually putting in our way. In this work Prof. Haldane has played a foremost part. Nor could anyone else have played a similar part. $\mathrm{He}$ has been responsible for bringing together the organic chemist and the geneticist in the work of discovering how the genes co-operate in producing plant pigments. He has likewise brought together genetic analysis and the study of abnormal development. He has also, with Fisher, developed a statistical instrument not only for making good the experimental shortcomings of human breeding but also for establishing medical genetics as a discipline of independent value and validity.

This work Haldane has briefly summarized in the present volume. The paths he maps are inevitably far apart from one another, and few readers will be equally interested in the different techniques he describes. Perhaps he might have done more to spread the interest by sparing or explaining his words. For they are, I imagine, the most impressive in strength and variety ever brought together in a volume of this size. But the general reader need not be deterred by these technical expressions, for they can mostly be replaced by symbols without loss to the argument; and in their present context the mathematical equations can be taken as a decoration.

Some readers may feel that if Haldane is approaching his problems in terms of formal geneties he is thereby missing important possibilities of deeper analysis. I do not think he is missing much. A danger lies merely in formal concepts being supposed to have an analytical finality. Two examples of possible misconception may be taken from this book. In Drosophila melanogaster and Zea Mays it is said "almost every gene has been located" (p. 17). By this is meant analytically "every gene-difference so far detected by experiment". The method of experimental breeding cannot be said to have located every gene since every gene has not necessarily mutated and some genes are not individually detect. able. Again (p. 108) it is inferred that "the normal allelomorphs of $W$ and $f$ control different unit processes", since the abnormal allelomorphs upset the control of these processes. This does not necessarily follow. It is a possibility. In the case of his amorphs, hypomorphs and hypermorphs, Muller has proved that the possibility may be realized. But in the case of other types of mutation he has equally proved that it is not and cannot be realized; which is a priori fairly obvious. The gene indeed as it exists in Nature is physiologically a somewhat informal body capable of breaking most physiological rules. The possibilities of rule-breaking that it is not likely to take advantage of are the mechanical ones such as those envisaged by Haldane (p. 110), of its running loose in the cytoplasm. That would be an offence against Nature since the reproductive cycle of the nuclear gene is naturally conditioned by its nuclear environment.

These objections like the others are no hindrance to Haldane's underlying argument. That argument is, in brief, that genetical analysis provides the key to problems in other fields which will baffle the wits and waste the labour of those who attempt to get along without it.
C. D. Darlington. 